\title{
PENGARUH INTERVAL TRAINING TERHADAP VO2 MAX PADA EKSTRA KURIKULER PENCAK SILAT PERSAUDARAAN SETIA HATI TERATE RAYON KHUSUS SMKN 1 NANGA PINOH
}

\author{
Kardianus ${ }^{1}$, Suyatmin $^{2}$, Nur Moh Kusuma Atmaja ${ }^{3}$ \\ ${ }^{1}$ Mahasiswa Penjaskesrek STKIP Melawi \\ ${ }^{2,3}$ Dosen Penjaskesrek STKIP Melawi \\ Jl. RSUD Melawi km. 04 Kec. Nanga Pinoh, Kab. Melawi Kalimantan Barat \\ Email: kardi.ashter22@gmail.com, \\ suyatminuny@gmail.com,atmajanur27@gmail.com
}

\begin{abstract}
This research aims to know the effect of Interval Training on $\mathrm{VO}_{2} \mathrm{Max}$ in the extracurricular Pencak Silat Brotherhood Faithful Heart Terate Rayon Special smkn 1 Nanga Pinoh. This research includes pre-experiment, with the sample not separate. The experimental method with the sample does not mean that the research has a single sample group, measured twice, the first measurement is done before the subject ispretests, then treatment, which is finally closed with a second measurement (posttest). The design used in this study was "The One Group Pretest Posttest Design" or the absence of a control group.The results of the previous study and discussion obtained obtained the calculated $T$ value (2.630) > $t$ Table (1.812), and the value of sig (2-tailed) (0.000) < of 0.05, the result indicates that the value of $T$ count is greater than in $T$ table. The result is interpreted Ha: accepted and Ho: rejected. If Ha accepted interpreted the effect of Interval Training on $\mathrm{VO}_{2}$ Max on the extra-curricular Pencak Silat Brotherhood of Faithful Heart Terate Rayon Special SMKN 1 Nanga Pinoh.
\end{abstract}

\section{Keywords: Interval Training, $\mathrm{VO}_{2}$ Max, Pencak Silat.}

\begin{abstract}
Abstrak: Penelitian ini bertujuan ingin mengetahui Pengaruh Interval Training Terhadap $\mathrm{VO}_{2}$ Max Pada Ekstra Kurikuler Pencak Silat Persaudaraan Setia Hati Terate Rayon Khusus SMKN 1 Nanga Pinoh. Penelitian ini termasuk pre-experiment, dengan sampel tidak terpisah. Metode eksperimen dengan sampel tidak terpisah maksudnya penelitianya memiliki satu kelompok sampel saja,yang diukur dua kali, pengukuran pertama dilakukan sebelum subjek diberi perlakuan (pretest), kemudian perlakuan (treatment),yang akhirnya ditutup dengan pengukuran kedua (posttest). Desain yang digunakan dalam penelitian ini adalah"The One Group Pretest Posttest Design" atau tidak adanya grup kontrol. Hasil penelitian dan pembahasan sebelumnya diperoleh nilai t hitung (2.630)>t Tabel (1.812), dan nilai sig (2-tailed) $(0,000)<$ dari 0,05 , hasil tersebut menunjukkan bahwa nilai t hitung lebih besar dari pada t tabel. Hasil tersebut diartikan Ha: diterima dan Ho: ditolak. Jika Ha diterima diartikan ada Pengaruh Interval Training Terhadap $\mathrm{VO}_{2} \mathrm{Max}$ Pada Ekstra Kurikuler Pencak Silat Persaudaraan Setia Hati Terate Rayon Khusus SMKN 1 Nanga Pinoh.
\end{abstract}

Kata kunci : Interval Training, $\mathrm{VO}_{2} \mathrm{Max}$, Pencak Silat. 
I ndonesia merupakan Negara yang menjadi pusat ilmu beladiri tradisional Pencak Silat asli Bangsa Indonesia yang sekarang sudah menjadi olahraga populer yang sudah mendunia.

Menurut Asep Kurnia Nenggala (2006) Pencak Silat memiliki 4 aspek yang terkandung di dalamnya yaitu: 1). Aspek Mental Spiritual 2). Aspek Seni Budaya 3). Aspek Bela Diri dan 4). Aspek olahraga. Dalam cabang Olahraga Pencak Silat ada beberapa kategori pertandingan yang dipertandingan dalam setiap pertandingan pencak silat, baik tingkat dewasa maupun tingkat pelajar seperti kategori laga, kategori tunggal, kategori ganda, dan kategori beregu. Pada kategori laga dalam satu babak dibutukan waktu 3 menit dan terdiri dari tiga babak maka total waktu dalam 3 babak adalah 9 menit dan 1 menit istirahat setiap babak. Sedangkan kategori seni terdiri atas kategori tunggal, ganda, dan beregu waktu penampilan dilakukan selama 3 menit.

Maksud dan tujuan untuk Ekstra Kurikuler Pencak Silat Persaudaraan Setia Hati Terate Rayon Khusus SMKN 1 Nanga Pinoh Yaitu: (1). Menjadi percontohan Pusat pelatihan atlit pelajar di Wilayah Kabupaten Melawi, (2). Menjadi Keluarga Besar Persaudaraan Setia Hati Terate (Warga PSHT), (3). Sebagai generasi muda yang setia menjaga dan melestarikan Budaya
Luhur Bangsa, (4). Membentuk kader-kader atlit Pencak Silat di SMKN 1 Nanga Pinoh yang mampu menaikan predikat sekolah, (5). Mampu mempertahankan bahkan menaikan Akreditasi Sekolah. Adapun jadwal latihan dilakukan 3 kali dalam satu minggu yaitu pada hari selasa, kamis dan minggu. Nawawi (2014:126) menjelaskan $\mathrm{VO}_{2} \mathrm{Max}$ adalah jumlah maksimum oksigen dalam mililiter, seseorang dapat digunakan dalam satu menit perkilogram berat badan, jadi $\mathrm{VO}_{2}$ Max atau kapasitas aerobik menggambarkan suatu kemampuan badan untuk mendapatkan oksigen, kemudian dikirim ke otot-otot dan sel-sel darah sebagai bahan bakar pada saat aktifitas dalam kurun waktu yang relatif lama.

Hubungan $\mathrm{VO}_{2}$ Max pada Ekstra Kurikuler Pencak Silat adalah agar siswasiswi mampu melakukan gerak dengan baik dan maksimal baik dalam waktu latihan maupun dalam pertandingan. Kualitas $\mathrm{VO}_{2}$ Max sangat menentukan kemampuan gerakan seorang pesilat baik atau tidaknya gerakan, karena kualitas $\mathrm{VO}_{2}$ Max merupakan salah satu penentu keberasilah suatu gerakan dalam meraih suatu prestasi. Untuk mengetahui kualitas $\mathrm{VO}_{2} \mathrm{Max}$ tes dan pengukuran $\mathrm{VO}_{2} \mathrm{Max}$ yang penulis gunakan yaitu mengunakan tes MFT (Multistage Fitness Test) dengan jarak 20 meter. 


\section{MFT (Multistage Fitness Test)}

adalah tes berlari terus menerus di antara dua garis yang berjarak 20 meter selama terdengar suara beep yang sudah direkam sampai kemampuan daya tahan maksimal atau disebut $\mathrm{VO}_{2} \mathrm{Max}$.

Tes $\mathrm{VO}_{2}$ Max Siswa-Siswi yang dilakukan pada tanggal 21 januari 2020 pukul 16.00 WIB di lapangan SMKN 1 Nanga Pinoh. Tes tersebut diikuti oleh 22 orang Siswa-Siswi. Perempuan berjumlah 16 orang, laki-laki berjumlah 6 orang dan usianya mulai dari 13 sampai 19 tahun. Siswa yang berusia 13 tahun berjumlah 1 orang, usia 14 tahun berjumlah 3 orang, usia 15 tahun berjumlah 7 orang, usia 16 tahun berjumlah 4 orang, usia 17 tahun berjumlah 5 orang, usia 18 tahun berjumah 1 orang, dan usia 19 tahun berjumlah 1 orang.

\section{$\mathrm{VO}_{2} \quad \mathrm{Max}$ Siswa-Siswi Ekstra} Kurikuler Pencak Silat Persaudaraan Setia Hati Terate Rayon Khusus SMKN 1 Nanga Pinoh masih pada kategori sangat kurang baik dengan jumlah 8 orang $(36,36 \%)$. $\mathrm{VO}_{2}$ Max Siswa-Siswi Ekstra Kurikuler Pencak Silat Persaudaraan Setia Hati Terate Rayon Khusus SMKN 1 Nanga Pinoh masih rendah atau masih banyak kategori sangat kurang. Adapun beberapa faktor yang menyebabkan $\mathrm{VO}_{2}$ Max masih sangat kurang baik disebabkan oleh beberapa faktor seperti faktor umur, makanan, kegiatan, jam istirahat, berat badan dan program latihan fisik khususnya metode interval training belum pernah diterapkan.

Berdasarkan hasil test MFT (Multistage Fitness Test) untuk meningkatkan kualitas $\mathrm{VO}_{2}$ Max SiswaSiswi Ekstra Kurikuler Pencak Silat Persaudaraan Setia Hati Terate Rayon khusus SMKN 1 Nanga Pinoh, Maka program latihan yang akan di berikan untuk meningkatkan kualitas $\mathrm{VO}_{2} \quad \mathrm{Max}$ yaitu dengan metode Interval Training. Bentuk Interval Training yaitu daya tahan Aerobik dan daya tahan anaerobik dengan lari interval jarak jauh dalam waktu yang cukup lama dan lari interval jarak pendek dengan waktu yang cepat.

Harsono, (1988:157) Interval training adalah suatu sistem atau metode latihan yang diselingi oleh interval-interval yang berupa masa-masa istirahat. beberapa faktor yang harus dipenuhi dalam menyusun interval training yaitu lamanya latihan,beban latihan, ulangan (repetition) melakukan latihan,Masa istirahat (recovery dan interval) setelah setiap repetisi latihan. Junusul Hairy, (2003) Keuntungan yang diperoleh dengan nmengunakan metode Interval Training dibandingkan dengan metode lainnya diantaranya adalah : 1) Pengontrolan latihan lebih teliti. 2) Lebih sistematis karena memungkinkan seseorang pelatih lebih mudah untuk mengetahui kemajuan dari hari ke hari. 3) Peningkatan 
potensi energi lebih lebih cepat dari pada metode Conditioning lainnya. 4) Program dapat dilakukan hampir dimana saja dan tidak memerlukan peralatan khusus.Tujuan dari penelitian ini yaitu untuk meningkatkan $\mathrm{VO}_{2} \mathrm{Max}$ Siswa-Siswi Pada Ekstra Kurikuler Pencak Silat Persaudaraan Setia Hati Terate Rayon Khusus SMKN 1 Nanga Pinoh.

\section{METODE PENELITIAN}

Dalam Penelitian ini adapun metode penelitian yang akan penulis gunakan adalah penelitian pra-eksperiment yaitu eksperimen Kuantitatif yang berhubungan dengan data angka-angka. Penelitian ini bertujuan untuk mengetahui pengaruh latihan interval training terhadap $\mathrm{VO}_{2}$ Max Pada SiswaSiswi Ekstra Kurikuler Pencak Silat Persaudaraan Setia Hati Terate Rayon Khusus SMKN 1 Nanga Pinoh. Desain Penelitian ini yang digunakan penulis yaitu termasuk jenis penelitian pra-experiment, dengan sampel tidak terpisah, karena tidak dapat mengontrol semua variabel yang mempengaruhi hasil eksperimen (Suharsimi Arikunto, (2002).

Metode eksperimen dengan sampel tidak terpisah maksudnya peneliti hanya memiliki satu kelompok (sampel) saja, yang diukur dua kali, pengukuran pertama dilakukan sebelum subjek diberi perlakuan (pretest), kemudian subjek diberikan perlakuan (treatment) yaitu dengan latihan program Interval Training,yang akhirnya ditutup dengan pengukuran akhir (posttest). Desain yang digunakan dalam penelitian ini adalah"The One Group Pretest Posttest Design" atau tidak adanya grup kontrol (Sukardi, 2009:18). Adapun Desain penelitian ini dapat digambarkan sebagai berikut:

\section{$\mathrm{OI} \times \mathrm{O} 2$}

Gambar 1.1 Desain penelitian

Keterangan :

O1 : Pretest (tes awal)

$\mathrm{X}$ : Treatment (perlakuan)

$\mathrm{O} 2$ : Posttest (tes akhir)

Desain penelitian tersebut di atas dapat dijelaskan bahwa subjek eksperimen diberikan pretest dengan kemampuan daya tahan maksimal ( $\left.\mathrm{VO}_{2} \mathrm{Max}\right)$. Penelitian ini hanya dilakukan pada satu kelompok eksperimen yang diberikan perlakuan berupa modifikasi latihan aerobik pendekatan teknik. Setelah subjek penelitian diberikan perlakuan, maka tahap akhir yang dilakukan adalah posttest. Apabila pada akhir ada perbedaan antara pretest dan posttest, maka hal itu disebabkan oleh pengaruh perlakuan yang diberikan.

$$
\text { Menurut Sugiyono }
$$
pengaruh perlakuan sama dengan hasil posttest dikurangi pretest. Populasi dalam penelitian ini adalah seluruh Siswa-Siswi Ekstra Kurikuler Pencak Silat PSHT Rayon Khusus SMKN 1 Nanga Pinoh dan Sampel 
Penelitian yang peneliti ambil yaitu berjumlah 11 orang. laki-laki 3 orang dan perempuan 8 orang adapun siswa-siswi yang saya ambil adalah (1). Siswa-Siswi Umur 15-18 (2). aktif mengikuti latihan, (c) sanggup mengikuti program latihan selama 12 kali pertemuan. Teknik Pengumpulan data yang dilakukan dalam penelitian ini adalah tes dan pengukuran. Adapun langkahlangkah pengumpulan data yaitu mengunakan instrumen MFT (Multistage Fitness Test).

Pelaksanaan Tes yaitu: 1). Hidupkan tape recorder yang berisi kaset atau $\mathrm{CD}$ panduan tes MFT (Multistage Fitness Test) mulai dari awal lalu ikuti petunjuknya. Pada bagian permulaan, jarak dua sinyal tut menandai suatu interval satu menit yang terukur secara akurat. Selanjutnya penjelasan ringkas mengenai pelaksanaan tes yang mengantarkan pada perhitungan mundur selama lima menit menjelang dimulainya tes, 2). Setelah itu akan keluar sinyal tut pada beberapa interval yang teratur. Peserta tes diharapkan berusaha agar dapat sampai ke ujung yang berlawanan bertepatan dengan sinyal tut yang pertama berbunyi, untuk kemudian berbalik dan berlari ke arah yang berlawanan. Setiap kali sinyal tut berbunyi peserta tes harus sudah sampai di salah satu ujung lintasan lari yang di tempuhnya. 3). Selanjutnya interval satu menit akan berkurang sehingga untuk menyelesaikan level selanjutnya peserta tes harus berlari lebih cepat. Setiap kali peserta tes menyelesaikan jarak 20 meter, posisi salah satu kaki harus tepat menginjak atau melewati batas 20 meter,selanjutnya berbalik dan menunggu sinyal berikutnya untuk melanjutkan lari ke arah berlawanan. Bila dua kali berurutan atlet tidak mampu mengikuti irama waktu lari berarti kemampuan maksimalnya hanya pada level dan balikan tersebut, 4). Setelah atlet tidak mampu mengikuti irama waktu lari, atlet tidak boleh terus berhenti, tetapi tetap meneruskan lari pelan-pelan selama 3-5 menit untuk cooling down.

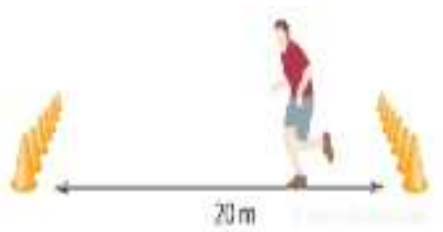

Gambar 3.3 MFT (Multistage Fitness Test)

(Sumber : Widiastuti,2011)

Dalam teknik pengumpulan data yang dikumpulakan dalam penelitian ini yaitu data $\mathrm{VO}_{2}$ Max yang diambil sebelum dan sesudah perlakuan, dengan tujuan melihat adakah pengaruh setelah dilakukan perlakuan. Data $\mathrm{VO}_{2}$ Max didapatkan dengan Tes MFT (Multistage Fitness Test).

\section{HASIL DAN PEMBAHASAN}

Pada Penelitian ini bermaksud untuk mengetahui data pretest dan data posttest Pengaruh Interval Training Terhadap $\mathrm{VO}_{2}$ Max Pada Ekstra Kurikuler Pencak Silat 
Persaudaraan Setia Hati Terate Rayon Khusus SMKN 1 Nanga Pinoh. Hasil penelitian ini diperoleh berdasakan hasil pretest 1 kali dan posttest 1 kali Penelitian ini dilaksanakan pada tanggal 1 sampai 29 Juni 2020. Treatment (perlakuan) dilakukan sebanyak 12 kali pertemuan dan total pertemuan sebanyak 14 kali.

Berikut ini hasil penelitian data pretest dan posttest dapat dideskripsikan sebagai berikut: 1). Data VO2 Max Pretest Dan Posttest Siswa-Siswi Ekstra Kurikuler Pencak Silat Persaudaraan Setia Hati Terate Rayon Khusus SMKN 1 Nanga Pinoh. Data Pretest merupakan data yang diambil sebelum peserta di berikan Program Interval Training. Data Posttest merupakan data yang diambil sesudah peserta di beri Program Interval Training Terhadap Ekstra Kurikuler Pencak Silat Persaudaraan Setia Hati Terate Rayon Khusus SMKN 1 Nanga Pinoh. Dari hasil data tabel Statistik hasil $\mathrm{VO}_{2}$ Max pretest dan posttest dapat di hitung berapa Frekuensi Statistik data Hasil Pretest $\mathrm{VO}_{2}$ Max Tes MFT (Multistage Fitness Test) yaitu: diikuti oleh 11 orang sampel dengan kategori cukup 1 orang (9 $\%$ ), kategori kurang berjumlah 9 orang (82 $\%)$, Sangat Kurang berjumlah 1 orang (9\%) total 11 orang $(100 \%)$. Setelah diberikan treatment (perlakuan) program interval training dilakukan Posttest (tes akhir) adapun data posttest sebagai berikut: ketegori cukup meningkat berjumlah 7 orang (63\%), kategori kurang berjumlah 4 orang $(37 \%)$ dan kategori sangat kurang (0 $\%)$ total 11 orang $(100 \%)$

\section{Analisis Data}

Analisis data dalam penelitian ini untuk mengetahui hasil uji normalitas, uji homogenitas dan uji hipotesisi (uji t). Hasil uji normalitas, uji homogenitas dan uji $\mathrm{t}$ dapat dilihat sebagai berikut:

\section{Uji Normalitas}

Tujuan uji normalitas adalah untuk mengetahui apakah data yang diperoleh dari tiap-tiap variabel yang dianalisis sebenarnya mengikuti pola sebaran normal atau tidak.Uji Normalitas variabel dilakukan dengan menggunakan rumus KolmogrovSmirnov.Kriteria yang digunakan untuk mengetahui normal tidaknya suatu sebaran adalah $\mathrm{p}>0,05$ sebaran dinyatakan normal,dan jika $\mathrm{p}<0,05$ sebaran dikatakan tidak normal.

Berdasarkan tabel di atas, hasil output diatas diketahui nilai signifikat sahpiro-wilk untuk variabel Pretest dan Posttest lebih besar dari 0,05 sehingga data $\mathrm{VO}_{2} \mathrm{Max}$ Siswa-Siswi Pada ekstra kurikuler Pencak Silat Rayon Khusus SMKN 1 Nanga Pinoh dapat disimpulkan berdistribusi normal.

\section{Uji Homogenitas}


Uji homogenitas berguna untuk menguji kesamaan sampel yaitu seragam atau tidak varian sampel yang diambil dari populasi. Hasil uji homogenitas penelitian berdaskan output di atas diketahui nilai signifikasi (Sig) Based on Mean adalah sebesar 0,931>0,05, sehingga data $\mathrm{VO}_{2}$ Max Siswa-Siswi Pada ekstra kurikuler Pencak Silat Rayon Khusus SMKN 1 Nanga Pinoh dapat disimpulkan homogen.

\section{Uji t (Paired Sample t Test)}

Uji $t$ dalam penelitian ini menggunakan uji $\mathrm{t}$ sampel berkorelasi (Paired Sample t Test) pada taraf signifikan $5 \%$. Dari data hasil t sampel correlation dengan nilai signifikasi $0,000<5 \%$, Maka dapat dikatakan ada hubungan antara interval training terhadap peningkatan $\mathrm{VO}_{2}$ Max. Uji t tersebut dimaksudkan untuk menjawab hipotesis yang telah diajukan. Pengujian hipotesis dilakukan untuk mengetahui penerimaan atau penolakan hipotesis yang diajukan. Berdasarkan hasil analisis data tersebut diperoleh nilai t hitung (2.630) > t Tabel(1.812), dan nilai sig (2tailed $)(0,000)<$ dari 0,05 , hasil tersebut menunjukkan bahwa nilai $\mathrm{t}$ hitung lebih besar dari pada $t$ tabel. Hasil tersebut diartikan Ha: diterima dan Ho: ditolak. Jika Ha diterima diartikan ada pengaruh interval training terhadap $\mathrm{VO}_{2}$ Max Pada Ekstra Kurikuler Pencak Silat Persaudaraan Setia
Hati Terate Rayon Khusus SMKN 1 Nanga Pinoh.

\section{PEMBAHASAN}

Penelitian ini dilakukan dengan tujuan untuk melihat data pretest dan posttest apakah ada pengaruh Program Interval Training terhadap $\mathrm{VO}_{2}$ Max Pada Ekstra Kurikuler Pencak Silat Persaudaran Setia Hati Terate Rayon Khusus SMKN 1 Nanga Pinoh pada Siswa-Siswi Ekstra Kurikuler Pencak Silat Usia 15-18 tahun. Sebelum diberikan treatment program interval training dilakukan pretest (tes awal) 1 kali yaitu untuk mencari data kemampuan $\mathrm{VO}_{2}$ Max awal. Berdasarkan hasil data Pretest diperoleh nilai minimum $=24,0 \mathrm{ml} / \mathrm{kg} / \mathrm{min}$, nilai maksimum $=39,2$ $\mathrm{ml} / \mathrm{kg} / \mathrm{min}$. Setelah dilakukan tes awal, kemudian sampel penelitian diberikan treatment yaitu program latihan dalam bentuk lari interval training yang dilakukan selam 12 kali pertemuan yang dilakuakan 3 kali seminggu yaitu hari selasa, kamis dan minggu. Sebelum melakukan latihan sampel penelitian wajib menghitung denyut nadi dan melakukan pemanasan statis dan dinamis supaya otot, jantung dan paru-paru siap untuk menerima beban latihan lari interval yang telah ditentukan.

Dalam program interval taraining ini sampel penelitian melakukan lari selama waktu yang ditentukan dan setelah waktu 
kerja habis sampel penelitian diberikan recovery atau interval (waktu istirahat per repitisi), kemudian setelah latihan inti selesai diakhir latihan sampel penelitian wajib melakukan cooling down agar otot, jantung dan paru-paru rileksasi dan kembali normal. Setelah diberikan treatment atau program interval training sampel penelitian dilakukan tes akhir (posttest) yaitu untuk melihat apakah ada pengaruh program interval training terhadap $\mathrm{VO}_{2}$ Max pada Ekstra Kurikuler Pencak Silat Persaudaraan Setia Hati Terate Rayon Khusus SMKN 1 Nanga Pinoh.

Data Posttest setelah diberikan Program Interval Training atau Treatment diperoleh nilai minimum $=26,8 \mathrm{ml} / \mathrm{kg} / \mathrm{min}$ nilai maksimum $=42,0 \mathrm{ml} / \mathrm{kg} / \mathrm{min}$. Dengan diberikan program interval training terdapat peningkatan $\mathrm{VO}_{2}$ Max yang signifikan yaitu nilai $\mathrm{VO}_{2}$ Max Minimum saat pretest 24,0 $\mathrm{ml} / \mathrm{kg} / \mathrm{min}$ kemudian peningkatan setelah diberikan treatment yaitu nilai minimum posttest 26,8 jadi peningkatan $\mathrm{VO}_{2}$ Max yaitu sebasar $2,8 \mathrm{ml} / \mathrm{kg} / \mathrm{min}$. Dan nilai maksimum pretest sebesar $39,2 \mathrm{ml} / \mathrm{kg} / \mathrm{min}$ setelah diberikan program interval taraining terdapat peningkatan $\mathrm{VO}_{2}$ Max dengan nilai maksimum sebesar 42,0 $\mathrm{ml} / \mathrm{kg} / \mathrm{min}$, kemudian peningkatan $\mathrm{VO}_{2} \mathrm{Max}$ setelah treatment yaitu sebesar 2,8 $\mathrm{ml} / \mathrm{kg} / \mathrm{min}$.
Dari hasil pretest dan Posttest Berdasarkan analisis SPSS 23 menunjukkan bahwa dengan mengikuti progam interval training berpengaruh signifikan terhadap $\mathrm{VO}_{2} \mathrm{Max}$ pada ekstra kurikuler Pencak Silat Persaudaran Setia Hati Terate Rayon Khusus SMKN 1 Nanga Pinoh,dengan $t$ hitung (2.630) > t Tabel(1.812), dan nilai sig (2-tailed) $(0,000)<$ dari 0,05, Maka dari itu dapat disimpulkan bahwa kajian teori dan beberapa jenis penelitian yang relevan lainnya setelah diterapkan di Ekstra Kurikuler Pencak Silat Rayon Khusus SMKN 1 Nanga Pinoh. Dengan acuan program latihan berdasarkan waktu sangat berpengaruh dalam meningkatkan $\mathrm{VO}_{2}$ Max.

\section{SIMPULAN}

Berdasarkan hasil penelitian dan pembahasan sebelumnya $\mathrm{VO}_{2}$ Max Pretest Maksimum yaitu sebesar $39,2 \mathrm{ml} / \mathrm{kg} / \mathrm{min}$ dan $\mathrm{VO}_{2}$ Max Posttest Maximum yaitu sebesar 42,0 $\mathrm{ml} / \mathrm{kg} / \mathrm{min}$ dan diperoleh nilai $\mathrm{t}$ hitung sebesar (2.630) > t Tabel (1.812), dan nilai sig (2-tailed) $(0,000)<$ dari 0,05 . hasil tersebut menunjukkan bahwa nilai $\mathrm{t}$ hitung lebih besar dari pada t tabel. Hasil tersebut diartikan Ha: diterima dan Ho: ditolak. Jika Ha diterima diartikan ada pengaruh Interval Training terhadap $\mathrm{VO}_{2}$ Max pada Ekstra Kurikuler Pencak Silat Persaudaraan Setia Hati Terate Rayon Khusus SMKN 1 Nanga Pinoh 


\section{DAFTAR PUSTAKA}

Asep Kurnia Nenggala. 2006. Pendidikan jasmani olahraga dan kesehatan. Jakarta: Grafindo Media Pratama.

Junusul Hairy. 2003. Daya Tahan Aerobik. Jakarta: Direktorat.

Harsono. 1988. Coaching dan Aspek-aspek Psikologis dalam Coaching. Bandung: Tambak Kusuma CV.

Sugiyono. 2009. Metode Penelitian Kuantitatif, Kualitatif dan $R \& D$, Bandung : Alfabeta.
Arikunto. 2002. Prosedur Penelitian Suatu Pendekatan Praktek (Edisi. Revisi).Jakarta:

Widiastuti. 2011. Tes dan Pengukuran Olahraga. Jakarta : PT Bumi Timur Jaya.

Sukardi.2009. Metodologi Penelitian Pendidikan (Kompetensi dan Praktiknya). Jakarta: Bumi Aksara.

Sukadiyanto \& Muluk, D. 2011. Pengantar teori dan metodologi melatih fisik. Bandung: Lubuk Agung. 